\section{A Real Options Model with Games Applied to the Rio de Janeiro Residential Real Estate Market}

\author{
Glaudiane Lilian de Almeida ${ }^{1}$ \\ ${ }^{1}$ Fluminense Federal University and Pontifical Catholic \\ University of Rio de Janeiro, Production Engineering and \\ Industrial Engineering Department, Rio de Janeiro, Brazil \\ Marco Antonio Guimarães Dias ${ }^{2}$ \\ ${ }^{2}$ Pontifical Catholic University of Rio de Janeiro, Eletrical \\ Engineering Department, Rio de Janeiro, Brazil \\ Luiz Eduardo Teixeira Brandáo ${ }^{3}$ \\ ${ }^{3}$ Pontifical Catholic University of Rio de Janeiro, Administration \\ Department and Industrial Engineering Department, Rio de Janeiro, Brazil \\ Carlos Patricio Mercado Samanez ${ }^{4}$ \\ ${ }^{4}$ Pontifical Catholic University of Rio de Janeiro, Industrial \\ Engineering Department, Rio de Janeiro, Brazil
}

\begin{abstract}
Purpose - To determine the optimal investment strategy in Nash equilibrium for the residential real estate market of Rio de Janeiro, considering the uncertainty in the demand for real estate and the number of active competitors in the market.
\end{abstract}

Design/methodology/approach - A Real Options Game model was developed. The parameters of the model were estimated with econometric tools using data from the Rio de Janeiro real estate market.

Findings - The quantitative results obtained are intuitive in the sense that the larger the number of competitors, the lower the level of demand required for investment in new units, whereas the greater the volatility of demand, the greater the demand threshold for the investment to be optimal.

Originality/value - This study modified the methodology of Grenadier (2002), providing a more adequate and robust specification of the uncertainty for the demand function, thus allowing more intuitive economic interpretations.

Keywords - Real Options; Game Theory; Investment under Uncertainty; Oligopolies
Received on:

09/02/2016

Approved on:

05/09/2018

Responsible Editor:

Prof. Dr. Eduardo Contani

Evaluation process:

Double Blind Review

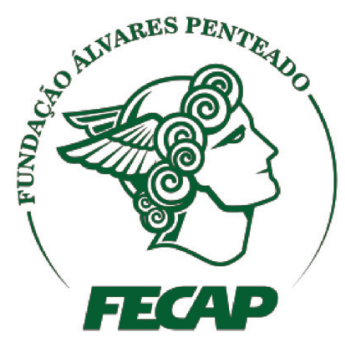

Review of Business Management 


\section{Introduction}

Investment decisions are characterized by strategic competition between rival firms, as each firm assesses its comparative advantages over its competitors and market conditions, such as product value, volatility of revenue streams, and market share, where monopolies and duopolies directly affect results. In this sense, investments in competitive markets can be seen as a game between firms, since in making investment decisions firms implicitly take into account the reactions of their competitors to their actions. As noted by Porter (1992), investment is the most important factor of competitive advantage.

Investment decisions are traditionally analyzed based on the discounted cash flow method (DCF), which consists of projecting the expected future cash flows and discounting them at the project's risk adjusted rate. One disadvantage of this method, however, is its simplistic and static nature, which does not capture the value of managerial and strategic flexibility and ignores the reactions of competing firms.

As these flexibilities have options-like characteristics, they can only be assessed using pricing options methods, such as the Real Options (RO) approach, which models the exogenous dynamic uncertainties of the economy (such as product demand) and the company's flexibilities to adapt to changing scenarios.

However, RO does not endogenously consider the possible competitive interactions. Game Theory, on the other hand, analyzes how firms make decisions when they are aware that their actions affect rival firms in the market and that they will respond rationally to the actions of their rivals. Therefore, a combination of Real Options with Game Theory has the potential to generate promising results for an analysis of investment decisions, given the complementarity between these two theories.

Choosing the ideal time to exercise the option of investing is critical to creating value in the company and to gaining competitive advantage.
In addition, decisions to invest or abandon a project involve different risks and uncertainties, especially in competitive environments where firms may have different optimal investment policies when compared to a monopolistic firm. This intersection of Game Theory with Real Options theory is known as Real Options Games, where competition is modeled endogenously, and the competitor enters rationally, not randomly, in addition to considering the uncertainties (stochastic processes) and flexibilities (RO).

In the classic case of real options, firms are only price takers and hold a monopoly over the option to invest, and ignore the fact that competition can affect the value of the real option as well as the optimal decision rule. In real options games, the firm's value maximization problem considers the presence of other firms as players, which react optimally to the relevant stochastic processes and the actions of other firms, enabling competition to be modeled in an endogenous way.

As noted by Grenadier (2002), a common issue in most papers that apply the Real Options approach is the lack of analysis regarding the strategic interactions of the holders of options where the optimal investment rule depends on the reaction of competitors to the project. Games with real options are seen as a way to overcome the shortcomings of the previously mentioned methods.

The objective of this paper is to determine the investment strategy in Nash equilibrium for the real estate market of the region of Rio de Janeiro, considering the uncertainty in the demand for real estate and the number of active competitors in the market.

To this end, a modified version of Grenadier's methodology was adopted with a more adequate and robust specification of the uncertainty for the demand function. Unlike previous studies, where traditional modeling of uncertainties was concentrated around multiplicative shocks in the demand function, it will be seen here that demand uncertainty is modeled from a multiplicative stochastic shock 
on its slope that includes a stochastic elasticity of demand factor.

This article is organized as follows. After this introduction, section 2 presents a review of the literature and section 3 develops the Real Options Game model. Following that, section 4 applies the proposed model to the residential market of the city of Rio de Janeiro and section 5 presents the results and the conclusions. The appendix presents some intermediate mathematical developments.

\section{Review of the Literature}

The first paper to address the contributions of combining Game Theory and Real Options Theory is attributed to Smit \& Ankum (1993), in which they demonstrated that competition among companies implies a decrease in the value of waiting, resulting in earlier investments. Dixit and Pindyck (1994) developed a basic model of Real Options Games for duopoly markets, where they evaluated investment timing.

Huisman (2000) proposed innovative models of real options games by adding to the literature the effect of technological uncertainty on the investment option, among other contributions. Chevalier-Roignant and Trigeorgis (2011) focused on other aspects of modeling real options, such as myopic investor behavior and capacity expansion.

Applications that use competitive structures from oligopolies were studied by Baldursson (1998) and Grenadier (2002) based on the result called "optimal myopia" for the competitive equilibrium discovered by Leahy (1993), as mentioned by Dixit and Pindyck (1994), where the optimal investment threshold (level of demand) of the monopolist case coincides with that of the perfect competition case, albeit for different reasons. In the case of the oligopoly in Grenadier (2002), with a modified demand function it is possible to use the concept of optimal myopia to obtain the solution in oligopolies, which will be used in this article. Murto et al. (2004) analyzed a game for oligopolies with stochastic demand, but in discrete time.
In Brazil, Costa et al (2015) studied the impact of preemption on optimal timing games for an asymmetric oligopoly applied in the Brazilian aluminum cans market and showed that firms need to anticipate their investments when there is a threat of preemption in the market, in relation to the case without competitors. Titman (1985) was the pioneer in applying the real options methodology to the real estate market, when he analyzed an option to postpone real estate investments in urban land. Williams (1991) considered an abandonment option as an alternative to land development, while Quigg (1993) and Holland et al (2000) provided empirical evidence that models based on the concept of real options may be useful in predicting values in real estate markets.

In the international literature, papers have been found that combine Real Options with Game Theory, such as that of Williams (1993), which derived symmetrical equilibrium exercise strategies for real estate developers by applying the model in the real estate market. Grenadier (1996) developed a game of real options in the real estate market suggesting a possible explanation for why some markets may experience booms in the face of declining demand and price depreciation. Grenadier (2005) made an equilibrium analysis for real estate leases using a Real Options Game model in a unified equilibrium approach to evaluate a wide variety of commercial real estate leases.

Wang and Zhou (2006) worked with demand and stochastic construction costs in a model with multiple real estate developers where the option to build a property could be exercised sequentially or simultaneously. The authors incorporated asymmetries in production capacity, allowing the impact of market power on the exercise strategies of the options to be examined.

In the national literature on $\mathrm{RO}$, we find the works of Rocha et al (2007) and Fortunato et al. (2008), who applied the Real Options Theory in the real estate sector in Rio de Janeiro. The Rocha et al. (2007) approach was based on 
a discrete-time real options model to identify the optimal strategy for simultaneous or sequential investments. This model allowed the maximum value to be paid for exclusive use of the land. Fortunato et al. (2008) used the real options theory to determine the value of the abandonment option during the construction period of an investment in a residential property acquired based on blueprints, considering different levels of return for the amounts already paid by the buyer. These two papers did not consider the effect of competition in an endogenous way, as in this study. Costa and Samanez (2008), as in this paper, analyzed the real estate market of Rio de Janeiro from the perspective of real options games, where they sought to determine the equilibrium between supply and demand, comparing with the real business cycle of the real estate market. Besides working with a sample that was not representative for Rio de Janeiro, they used arbitrary and exogenous values as proxies for their estimates, as have most of the studies that have applied models of Real Options Games. The quantification of competitive pressures can be seen in the calculation of thresholds that vary according to the number of companies, demonstrating that companies are more engaged in the market.

This paper differs from existing ones by modifying the Grenadier (2002) model specification for the demand function to a particularly robust format that allows a more intuitive economic interpretation. To the best of our knowledge, this is the first study of Real Options Games that makes use of a stochastic demand function in which the stochastic variable changes the slope of the demand curve. Moreover, the parameters of the model were estimated using econometric tools for real estate data, unlike several models of RO Games that have used exogenous values for the parameters, which may be subjective and arbitrary choices. This can be found in studies such as Grenadier (1996), Grenadier (2000), Grenadier (2002), and Grenadier (2005).

\section{The Model}

The Grenadier model (2002) was used because it is a classic model for this theme. In addition to developing an original approach with respect to the competition structure for oligopolies, Grenadier (2002) obtained an analytical solution for the oligopoly case as a single-agent optimization problem, which greatly facilitates the analysis.

The stochastic shock proposed in the modified demand used in this article includes a parameter that represents the elasticity of the stochastic demand factor, which allows for better economic interpretations when compared to Grenadier's work. Moreover the demand parameters were estimated from actual data, unlike most Real Options Game studies, as already highlighted.

The model developed in this section considers an oligopolistic industry with $n$ equal firms, where the number of firms is fixed, but each can produce more than one unit. In this oligopoly, each firm has a sequence of investment opportunities equivalent to perpetual American call options. Although real estate construction requires time to complete (time to build), for the sake of simplicity, we assume that all construction will be immediate (or that the amounts are already in present value on the exercise date), and that company $i$ produces units of an infinitely divisible product.

Based on concepts of Game Theory such as the perfect Cournot-Nash equilibrium, strategies are quantities and the market provides the equilibrium price for each state of demand. Real estate investors regard quantities $Q_{-i}^{*}$ as the best responses of competitors and maximize their profits by choosing the quantities to be produced $q_{i}^{*}(t)=1,2, \ldots n$. With equal firms, we have symmetric Nash equilibria (NE) and the optimal production of each firm in this symmetric oligopoly in NE is $q_{i}^{*}(t)=Q^{*}(t) / n$.

The industry supply process is $Q(t)=\sum_{j=1}^{n} q_{j}(t)$, and the supply of all firms 
except firm $i$ is given by $Q_{-i}(t)=\sum_{j=1, j \neq i}^{n} q_{j}(t)$. Given the current state of the industry, the profit stream of firm $i$ is determined by Eq. :

$$
\pi_{i}\left[X(t), q_{i}(t), Q_{-i}(t)\right] \equiv q_{i}(t) \times D\left[X(t), q_{i}(t)+Q_{-i}(t)\right]
$$

The demand function $\mathrm{D}$ is such that the conditions $\frac{\partial^{2} \partial_{i}}{\partial X \partial q_{i}}>0$ and $\frac{\partial^{2} \partial_{i}}{\partial q_{i}^{2}}<0$ are valid for all $i$. At any moment in time each company can invest in additional capacity to increase its production by an infinitesimal amount $d q_{i} \equiv d Q / n$ . If all firms increase their capacity simultaneously, will have an increase equivalent to $d Q$. The cost of this increment is linear so that it involves a cost $K$ per unit produced. The option to increase capacity is exercised by firm $i$ when $X(t)$, which represents the multiplicative shock in demand, reaches the threshold $X_{i}^{*}\left(q_{i}, Q_{-i}\right)$. The exogenous shock in demand $X(t)$ follows a stochastic diffusion process in the form of Eq. (2):

$$
d X=\mu(X, t) d t+\sigma(X, t) d z
$$

where $z(t)$ is the standard Wiener process. If $\mu(X, t)=\mu X$ and $\sigma(X, t)=\sigma X$, then $X(t)$ follows a Brownian Geometric Motion (BGM), with a lognormal distribution. As is standard in the literature, the cash flow is evaluated in the risk-neutral measure, and thus the discount rate has to be risk-free rate $r$. The unit price $P(t)$ is given by the inverse demand function $P(t)=D[X(t), Q(t)]$. This function will be specified in item 3.2.

\section{I Composition of the equilibrium model}

According to Grenadier's proposition 1 , the equilibrium value of each firm $i$ will be described as $V^{i}\left(X, q_{i}, Q_{-i}\right)$. The investment strategy in the NE for each firm is characterized by an incremental increase of its production whenever X ( $t$ ) reaches a threshold (level of demand). The ordinary differential equation (ODE) of $V^{i}\left(X, q_{i}, Q_{-i}\right)$ is given by Eq. (3). Its derivation is described in Appendix I.

$$
\frac{1}{2} \sigma^{2}(X, t)^{2} V_{X X}^{i}+\mu(X, t) V_{X}^{i}-r V^{i}+\pi_{i}\left(X, q_{i}, Q_{-i}\right)=0
$$

Eq. (3) is a perpetuity, where $V_{t}^{i}=0$, which is a characteristic of real estate projects, where the call option is perpetual, and there is no date for exercising the option. The boundary conditions are:

i) Continuity condition (value matching): at the threshold, the value of waiting (ODE solution) is equal to the exercise payoff of the option. That is, if $X(t)=X^{*}\left(q_{i}, Q_{-i}\right)$; $V_{q_{i}}^{i}\left(X^{*}, q_{i}, Q_{-i}\right)=K$ - condition at the optimal threshold of the firm, which exercises its option at $X^{*}$, expanding its production by investing $I d q$;

ii) Smooth-pasting condition: if $X(t)=X^{*}\left(q_{i}, Q_{-i}\right) ; V_{q_{i}}^{i}\left(X^{*}, q_{i}, Q_{-i}\right)=0$
- optimal condition of firm $i$, that is, at the optimal threshold for investing, the derivative of the waiting value and the exercise payoff are also equal.

iii) Condition of continuity at the thresholds of competitors, which in the symmetrical case are the same $X^{*}$ : if $X(t)=X^{*}\left(q_{i}, Q_{-i}\right) ; \mathrm{V}_{q_{i}}^{i}\left(X^{*}, q_{i}, Q_{-i}\right)=0$, t $\mathrm{h}$ e $\mathrm{r}$ e $\mathrm{f}$ o $\mathrm{r}$ e $V^{i}\left(X^{*}, q_{i}, Q_{-i}\right)=V^{i}\left(X^{*}, q_{i}, Q_{-i}+d Q_{-i}\right)$. This is a condition of strategic interaction, requiring each firm $i$ to maximize its value $V^{i}\left(X, q^{i}, Q_{-i}\right)$ by considering the strategies of the competitors. However, this condition will not be necessary, as Grenadier shows in his proposition 2, thus 
expanding the optimal myopic concept for oligopolies.

The ODE (Eq. (3)) and the three boundary conditions compose Grenadier's proposition 1, which summarizes the equilibrium. Considering continuous time and a perfectly competitive equilibrium scenario (Leahy, 1993), it has been shown that the investment policy of each firm is identical to the myopic strategy where the company ignores the effect competitors have on the value of the options. Thus, the exercise strategy is developed as if the firm were alone in the market, thus leading to a myopic strategy for exercising the real options. With this, the equilibrium can be established with only two boundary conditions (continuity and smoothpasting).

The value of the myopic firm is denoted by $M^{i}\left(X, q_{i}, Q_{-i}\right)$. Let the marginal value of the myopic firm's output be $m^{i}\left(X, q_{i}, Q_{-i}\right)$, given by Eq. (4):

$$
m^{i}\left(X, q_{i}, Q_{-i}\right)=\partial M^{i}\left(X, q_{i}, Q_{-i}\right) / \partial q_{i}
$$

Using symmetry, we can write $X^{i}\left(q_{i}, Q_{-i}\right)^{*}=X^{*}(Q)$, because $q_{i}=Q / n$ and $Q_{-i}=(n-1) \cdot Q / n$. In symmetric NE each firm will exercise its option at the threshold $X^{*}(Q)$. The ODE of the value of the myopic firm $M^{i}\left(X, q_{i}, Q_{-i}\right)$ is given by:

$$
1 / 2 \sigma^{2} M_{X X}^{i}+\mu(X) M_{X}^{i}-r M^{i}+(Q / n) D(X, Q)=0
$$

Let $\mathrm{X}^{* *}$ be the myopic firm's trigger, where the boundary condition of continuity is satisfied if $X(t)=X^{* *}\left(q_{i}, Q_{-i}\right) ; M_{q_{i}}^{i}\left(X^{* *}, q_{i}, Q_{-i}\right)=I$. Because the firm is myopic, it ignores competition by exercising the option at the myopic threshold $X^{* *}$ equivalent to $X^{*}$ of $V^{i}$ (Grenadier's proposition 2). The smooth-pasting condition will be satisfied for $X(t)=X^{* *}\left(q_{i}, Q_{-i}\right) ; M_{q_{i} X}^{i}\left(X^{* *}, q_{i}, Q_{-i}\right)=0$. Because it is myopic, the firm ignores the competition, so there are no competition boundary conditions. In this sense, the marginal value of the production of the myopic firm will be defined by the partial derivative of $M_{q_{i}}^{i}=m^{i}(X)$. In this study, this differential equation was used in order to focus on the case of the perfect competition structure by applying Leahy's (1993) optimal myopia.

Let $(X, Q)$ be the marginal value of the myopic firm. It can be verified by a process similar to that adopted in Appendix I where the value equation is given by Eq. (6):

$$
\frac{1}{2} \sigma(X)^{2} m_{x x}+\mu(X) m_{X}-r m+D(X, Q)+(Q / n) D_{Q}(X, Q)=0
$$

Eq. (6) and two boundary conditions at the threshold $X^{*}(\mathrm{Q})$ represented by Eqs. (7) and (8) are sufficient to determine $X^{*}(Q)$ and $m(X, Q)$.

$$
\begin{gathered}
m\left(X^{*}(Q), Q\right)=K \\
\partial m\left(X^{*}(Q), Q\right) / \partial X=0
\end{gathered}
$$

The terms of the cash flows of Eq. (6) constitute the non-homogeneous part of the ODE and comprise the modified demand function. The next step in this paper will provide the analytical solution to the ODE (Eq. (6)). The strategic threshold is equal to the "myopic" threshold $\mathrm{X}^{*}$ (see Grenadier's proposition 2). 
The format of the ordinary differential equation is applied to any stochastic process of Itô. Here the GBM will be used: $\mu(X, t)=\mu X$ and $\sigma(X, t)=\sigma X$, where $\mu$ is the expected growth rate of demand and $\sigma$ is the volatility of demand.

\subsection{The oligopoly model under uncertainty: analytical solution}

The oligopoly can be solved simply as a single agent optimization problem. For this, the oligopolistic industry follows a perfect competition structure if a modified or fictitious demand function $D^{\prime}$ is used (Grenadier, 2002):

$$
D^{\prime}(X, Q)=D(X, Q)+(Q / n) D_{O}(X, Q)
$$

For uncertainty in demand, X ( $t$ ) follows a GBM, which is the stochastic process most commonly used in the $\mathrm{RO}$ literature. In $\mathrm{RO}$ game modeling, market uncertainty is usually associated with demand. Here, unlike in other papers on Real Options Games, the following is assumed to be the inverse stochastic demand function, which is linear in $Q$ and with a stochastic slope:

$$
D(X, Q)=a+b(X(t))^{-\mathcal{E}} Q(t)
$$

where $a>0$ and $b<0$ to ensure that $\mathrm{D}_{\mathrm{Q}}<0$, and the exponent represents an elasticity. So, Eq. (9) is recalculated from the specification of the linear stochastic demand (Eq. (10)). Rewriting (9), we have the general representation for the non-homogeneous cash flows that define the nonhomogeneous term of Eq. (6), equal to Eq. (11):

$$
a+b Q X^{-\varepsilon}\left[\frac{n+1}{n}\right]
$$

A particular solution must be found for the non-homogeneous part of Eq. (6) that meets the entire ODE. Such a particular solution can be given by the present value equation of the cash flow in perpetuity (Eq. (12)):

$$
C=\frac{a}{r}+\frac{b Q\left[\frac{n+1}{n}\right] X^{-\varepsilon}}{\left[r+\mu \varepsilon-\left(\sigma^{2} / 2\right) \varepsilon(1+\varepsilon)\right]}
$$

The next step is to verify if the particular solution given by Eq. (12) satisfies the entire ODE. For this, (11) should be substituted as non-homogeneous terms of the cash flow of Eq. (6), in addition to the partial derivatives:

$$
\begin{aligned}
& \frac{\partial m}{\partial X}=\frac{b Q(-\varepsilon) X^{(-\varepsilon-1)}\left[\frac{n+1}{n}\right]}{\left[r+\mu \varepsilon-\left(\sigma^{2} / 2\right) \varepsilon(1+\varepsilon)\right]} \\
& \frac{\partial^{2} m}{\partial X^{2}}=\frac{\left(\varepsilon^{2}+\varepsilon\right) b Q X^{(-\varepsilon-2)\left[\frac{n+1}{n}\right]}}{\left[r+\mu \varepsilon-\left(\sigma^{2} / 2\right) \varepsilon(1+\varepsilon)\right]}
\end{aligned}
$$

Making the appropriate substitutions and with some algebraic effort it is verified that Eq. (12) is the particular solution that meets ODE (6). Thus, Eq. (6) can be rewritten in the complete (homogeneous and non-homogeneous) format that will allow us to find the solution for $\mathrm{X}^{*}(\mathrm{Q})$ (Eq. (15)):

$$
\frac{1}{2} \sigma(X)^{2} m_{x x}+\mu(X) m_{X}-r m+C=0
$$

It is observed that the first three terms of Eq. (15) form a homogeneous and parabolic ODE that has a general analytical solution in the form of Eq. (16):

$$
m(X)=A X^{\beta}
$$


where $\beta$ is a parameter and $A$ is a constant that, together with the threshold $X^{*}$, will be obtained through two boundary conditions. Dixit and Pindyck (1994) explain that to determine the parameter $\beta$, it is necessary to find the roots of the quadratic equation generated from the substitution of Eq. (16) and its partial derivatives in the homogeneous part of the ordinary differential Eq. (15):

$1 / 2 \sigma^{2} X^{2} A \beta(\beta-1) X^{\beta-2}+\mu X A \beta X^{\beta-1}-r A X^{\beta}$

After some algebraic manipulations, the term $A X^{\beta}$ is canceled and the characteristic quadratic equation of the homogeneous part of the ODE is obtained:

$$
1 / 2 \sigma^{2} \beta(\beta-1)^{2}+\mu \beta-r=0
$$

Eq. (17) is a quadratic equation that has two roots for $\beta$. Being a quadratic equation, the two roots of $\beta$ can be easily found:

$$
\beta_{1}=\frac{1}{2}-\frac{\mu}{\sigma^{2}}+\sqrt{\frac{2 r}{\sigma^{2}}+\left[\frac{\mu}{\sigma^{2}}-\frac{1}{2}\right]^{2}}>1
$$

$$
\beta_{2}=\frac{1}{2}-\frac{\mu}{\sigma^{2}}-\sqrt{\frac{2 r}{\sigma^{2}}+\left[\frac{\mu}{\sigma^{2}}-\frac{1}{2}\right]^{2}}<0
$$

with two roots, the homogeneous solution is given by a linear combination of the two solutions: $m(X)=A_{1} X^{b 1}+A_{2} X^{b 2}$. But because $b_{2}$ is negative, it is necessary that $A_{2}=0$, otherwise, when the demand shock $X$ tends to zero, the firm value will tend to infinity, which makes no economic sense.

Considering the conditions of continuity and smoothness in the threshold $\mathrm{X}^{*}$, given by Eqs. (7) and (8), we arrive at a system with two equations and two unknowns $\left(A_{1}\right.$ and $\left.X^{*}\right)$ :

$$
\left\{\begin{array}{l}
A_{1} X^{* \beta_{1}}+C=k \\
A_{1} \beta_{1} X^{*\left(\beta_{1}-1\right)}-\varepsilon X^{*-1} C=0
\end{array}\right.
$$

Solving the system, we determine the constant $A_{1}$ and the threshold :

$$
A_{1}=\frac{b Q(\varepsilon)\left[\frac{n+1}{n}\right] X^{\left(-\varepsilon-\beta_{1}\right)}}{\left[r+\mu \varepsilon-\left(\sigma^{2} / 2\right) \varepsilon(1+\varepsilon)\right]}
$$

Substituting (22) into the first equation of the system given by (21), we obtain:

$$
r b Q\left[\frac{n+1}{n}\right] X^{(-\varepsilon)}+a \beta_{1}\left[r+\mu \varepsilon-\left(\sigma^{2} / 2\right) \varepsilon(1+\varepsilon)\right]+r \beta_{1} b Q\left[\frac{n+1}{n}\right] X^{(-\varepsilon)}=k r \beta_{1}\left[r+\mu \varepsilon-0,5 \sigma^{2} \varepsilon(1+\varepsilon)\right]
$$

which, by simplifying and rearranging, gives us:

$$
X^{-\varepsilon}=\frac{\beta_{1}(k r-a)\left[r+\mu \varepsilon-0,5 \sigma^{2} \varepsilon(1+\varepsilon)\right]}{\left(\beta_{1}+\varepsilon\right) r b Q\left[\frac{n+1}{n}\right]}
$$


By rearranging the terms, we arrive at the expression for the optimal threshold in Nash equilibrium, represented by Eq. (23):

$$
X *(Q)=\left\{\left(\frac{\beta_{1}}{\beta_{1}+\varepsilon}\right)\left(\frac{r k-a}{r b Q\left[\frac{n+1}{n}\right]}\right)\left[r+\mu \varepsilon-\left(\sigma^{2} / 2\right) \varepsilon(1+\varepsilon)\right]\right\}^{(-1 / \varepsilon)}
$$

The result generated by the analytical solution of this model under uncertainty is important because it allows the extension of results with a simplified analytical solution in the case of perfect competition to an oligopoly model. In oligopolies, firms add capacity (they exercise the real option) in such an amount that the price goes down, due to the additional supply. It is possible to notice that the threshold $X^{*}(Q)$ decreases with the number of firms in the oligopoly (n).

The dynamics of options exercises when demand $X$ reaches the threshold $X^{*}$ can be identified when all $n$ firms exert their expansion options and add supply to the industry, so prices cannot exceed a maximum level. When exercising the strategic option in an oligopoly of $n$-firms, there is an option premium, which can be defined as the NPV at $X^{*}(Q)$ per unit of investment.

\section{Numerical Application: The residential real estate market of the city of Rio de Janeiro}

The real estate market of the city of Rio de Janeiro underwent several transformations that led it to having what was considered to be the most expensive square meter in Brazil in the beginning of the 2010s. Among the factors contributing to the overheating of Rio de Janeiro's real estate sector were the political and economic scenario, the expansion of credit, the increase in the average income of the population, the implementation of the pacifying police units (UPPs), and the expectations of positive returns from investments for the 2014 World Cup and 2016 Olympics.
With investments in infrastructure, sanitation, urban mobility, and civil construction aimed at preparing the city for the Olympic Games, since 2010 the real estate market of Rio de Janeiro has grown steadily and real estate property has become a synonym for profitable investment in the city.

According to Secovi-Rio (Union of Companies for the Purchase, Sale, Leasing, and Administration of Real Estate and Residential and Commercial Condos in the State of Rio de Janeiro), due to their proximity to the competition venues, neighborhoods such as Barra da Tijuca, Center, Jacarepaguá, Maracanã, and Tijuca saw an appreciation of real estate lease prices from $20 \%$ to $152 \%$ in a period of six months after the announcement of the International Olympic Committee.

Traditionally, investments in real estate markets are characterized as capital intensive and low liquidity, in addition to featuring sources of uncertainty in demand, prices, and construction costs that increase the risk perceived by investors. To estimate the parameters of the model, we used series for monthly average values per square meter of two-bedroom residential apartments, which are the standard model indicated as a representative sample of the reality of the real estate market of the region chosen for analysis. According to Secovi-Rio (2015), two-bedroom apartments are the ones with the highest demand and supply and the highest liquidity among the options of the residential real estate market.

One of the limitations of these historical series of sale prices of residential apartments is that they do not feature equalization of the data to allow price differences to be considered 
between units of the same size but with different characteristics, such as floor height, view, state of conservation, distance from the beach, fashionable streets, parking space, etc. Such characteristics may lead to price series that do not reflect actual price changes. The following is a brief description of the data used.

\section{I Data}

The historical series for the sale prices of real estate located in the 17 neighborhoods belonging to the municipality of Rio de Janeiro starts in June 2009 and ends in January 2016 and were made available by Secovi-Rio (http://www. secovirio.com.br/Produtos-e-Servicos/Pesquisase-Indicadores-163, retrieved on February 2, 2016)

The limited data provided by SecoviRio caused the analysis to be restricted to the 17 districts shown in Table 1, which shows the average nominal values per square meter of each neighborhood that forms the representative group of the region analyzed in this study.

Table 1

\section{Average nominal values per $\mathrm{m}^{2}$ from July 2009 to January 2016}

\begin{tabular}{|c|c|c|c|}
\hline \multirow{2}{*}{ Neighborhoods } & \multicolumn{3}{|c|}{ Average nominal values $\left(\right.$ per $\left.\mathrm{m}^{2}\right)$ in $\mathrm{R} \$(\mathrm{BRL})$} \\
\hline & Sale value & Rent & Condominium \\
\hline Barra da Tijuca & 7,443 & 30.96 & 9.78 \\
\hline Botafogo & 9,809 & 38.70 & 7.28 \\
\hline Centro & 5,878 & 25.62 & 5.52 \\
\hline Copacabana & 10,112 & 39.67 & 7.05 \\
\hline Flamengo & 9,128 & 35.07 & 6.63 \\
\hline Gávea & 13,508 & 46.75 & 8.40 \\
\hline Ilha do Governador & 4,003 & 16.87 & 3.82 \\
\hline Ipanema & 14,985 & 59.70 & 8.66 \\
\hline Jacarepaguá & 3,926 & 15.57 & 5.53 \\
\hline Jardim Botânico & 12,327 & 44.50 & 7.95 \\
\hline Lagoa & 13,638 & 48.25 & 8.84 \\
\hline Laranjeiras & 8,646 & 33.60 & 6.61 \\
\hline Leblon & 16,871 & 58.38 & 8.63 \\
\hline Méier & 3,686 & 15.41 & 5.33 \\
\hline Recreio & 5,962 & 22.95 & 6.75 \\
\hline Tijuca & 5,553 & 23.49 & 5.76 \\
\hline Vila Isabel & 4,570 & 20.24 & 5.32 \\
\hline Average & 8,826 & 33.87 & 6.93 \\
\hline
\end{tabular}

Note. Source: "Panorama do mercado imobiliário do Rio de Janeiro 2015", by SECOVI-Rio 2015, retrieved from http://www.secovirio.com.br/Produtos-e-Servicos/Pesquisas-e-Indicadores-163

\subsection{Estimation of model parameters}

In order to estimate the parameters of the model, we used the average price series deflated by the IPCA, constructed from the average nominal prices of the set of neighborhoods shown in Table 1. In relation to the stochastic process modeling, Dixit and Pindyck (1994) recommend that the suitability of the stochastic process to the evolution of the series of the analyzed asset be confirmed through econometric tests.

One test traditionally used to examine whether the series is non-stationary is the Augmented Dickey Fuller (ADF) test. However, Pindyck (1999) suggests that the ADF test is not sufficient to determine the stochastic process 
choice and proposes the variance-ratio test as an alternative. This test provides more information about the behavior of the series than the unit root test, by measuring the degree to which the variance of the series grows as the number of lags increases. The test is described by Eq. (25):

$$
R_{k}=\frac{1}{k} \frac{\operatorname{Var}\left(p_{t-k}-p_{t}\right)}{\operatorname{Var}\left(p_{t+1}-p_{t}\right)}
$$

For the GBM, the ratio of variances approaches 1 as $\mathrm{k}$ grows, with the variance increasing linearly with $k$. From the variation of the lags from 2 to 79 of the logarithms of the deflated price series, the results of this test indicated that the variance ratio increased with an increase in the number of lags. This behavior is consistent with a model in which prices behave as a Geometric Brownian Motion. The next step is to estimate the parameters of the GBM.

As in Dias (2015), the parameters $\boldsymbol{\alpha}$ and $\sigma$ can be estimated from the trivial

linear regression in discrete time with consecutive observations (Eq. (26)).

$$
\ln [P(t)]=\Theta+\ln \left[\left(P_{t-1}\right)\right]+\varepsilon_{t}
$$

where $\varepsilon_{t}$ is the error of the regression and has a normal distribution and parameters $\varepsilon_{t} \sim N\left(0, \sigma^{2} / N\right)$, and $N$ represents the number of periods per year of data observation, which in this study was $\mathrm{N}=12$. The parameters of the GBM were estimated with Eqs. (27) and (28).

$$
\begin{gathered}
\mu=N\left\{E\left[\ln \left[P_{t} / P_{t-1}\right]\right]+\sigma^{2} / 2 N\right\} \\
\sigma^{2}=N \operatorname{Var}\left[\ln \left[P_{t} / P_{t-1}\right]\right]
\end{gathered}
$$

In the regression equation (26) it was assumed that the $\ln \left(P_{t-1}\right)$ coefficient is equal to one, which is analogous to the discrete equation GBM. The dividend rate was calculated by

the ratio $\delta=\frac{\text { rent }+ \text { condominium }}{\text { property value }}$ (Costa $\&$
Samanez, 2008). The value of $5.54 \%$ was found for the average dividends of the analyzed region. This result shows if the owner can benefit from deciding to rent his or her apartment, so either the dividend rate must be compared with other rates of return on investments or even with savings.

Because real estate investment projects have long-term characteristics, it is reasonable to use a long-term interest rate as well. Therefore, the risk-free interest rate (r) used in this study is based on the Brazilian Government's 10-year maturity sovereign bond rate of return, currently $10.88 \%$ p.a. (https://www.bloomberg.com.br/, retrieved on June 20, 2017).

Given this information, the annual percentage values of the estimates for the trend () and the volatilities () are 5.51\% and $16.44 \%$ per year, respectively. The quantity supplied is determined exogenously to the model, so the value used for $\mathrm{Q}(\mathrm{t}=0)$ was 12,550 apartments (source: Secovi-Rio). This value was transformed into square meters, considering 60sqm footage, which is the standard average size of the two-bedroom apartments. The next step was to estimate the parameters of the demand equation (Eq. (10)).

The stochastic variable chosen was the monthly series of real prices of properties with 1 lag. The first step was to explain how X (t) affects demand. For this, an ARIMA process was identified through the autocorrelation function (ACF) and partial autocorrelation function (PACF). It was found that it was declining in the ACF and truncated in order 1 in the PACF. Thus, it was found that $\mathrm{X}(\mathrm{t})$ involves a first-order autoregressive process. Therefore, by applying the logarithm on both sides of Eq. (10), it was possible to estimate, through a linear regression, the parameters of interest for the calculation of the threshold in the Nash equilibrium, namely: $\alpha=9715,23, b=-0,031$, and $\varepsilon=0,97$.

\section{Results and Sensitivities}

From the modeling of stochastic processes developed in Section 4, we used the parameters estimated from the real estate market data, 
such as $\sigma$ and $\mu$. In addition to the parameters involved in the demand equation, the risk-free rate $\mathrm{r}$, the initial supply quantity $Q(t=0)$, the elasticity of the stochastic process $\varepsilon$, the investment $(\mathrm{K})$ defined in the model as being equal to one unit, and the parameters $a$ and $b$ of the demand equation are necessary variables for the solution of the model.
As a way of simplifying the analysis it was considered that the construction companies or developers already have the land to start construction. The critical values of $X^{*}(Q)$ represent the investment threshold in the Nash equilibrium and are presented in Table 2.

Table 2

Relationship between optimal thresholds and the number of competing companies

\begin{tabular}{lcccccc}
\hline No $^{\text {firms }}$ & 2 & 4 & 5 & 7 & 9 & 10 \\
\hline $\mathbf{X}^{*}(\mathbf{Q})$ & 4.74 & 3.92 & 3.77 & 3.58 & 3.47 & 3.44 \\
\hline
\end{tabular}

Thus, in the context of real-world investment, the financial return of a company is linked to the investment strategies of its competitors. The results of Table 2 show the effects of competition in determining the thresholds. In the case of a duopoly $(n=2)$, the optimal trigger in $\mathrm{NE}$ was $\mathrm{R} \$ 4.74$ per investment unit. Analyzing oligopolistic structures of 3 companies, for example, when considering 4 competing companies, the optimal trigger for investment is equal to $R \$ 3.92$, reducing to $R \$ 3.44$ per unit of investment when 10 competing companies are incorporated into the oligopoly model developed.

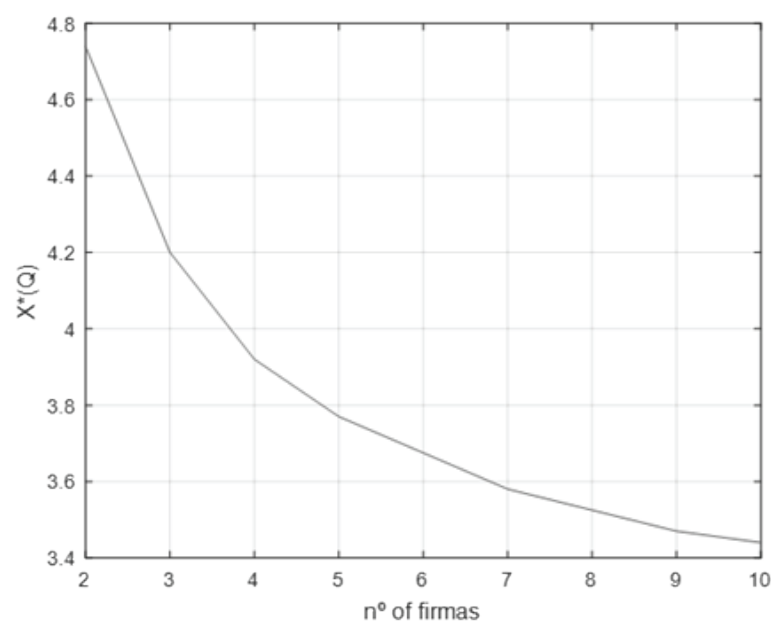

Figure 1. Optimal triggers vs. $n^{\circ}$ of competing firms
Figure 1 illustrates a situation in which the trigger decreases with increasing competition, since $X^{*}(Q)$, defined by Eq. (23), is a decreasing function of $n$. This can be seen as the behavior of a company $i$ given the entry of one or more rivals, in which the option to defer becomes less valuable, leading developers to exercise their options earlier.

Given the main results of the model developed in this article, it is important to illustrate a comparison between the variations in optimal equilibrium thresholds in relation to the various variables of the model. The thresholds were recalculated by stressing the main parameters that appear in the threshold equation (Eq. (23)). For each case, Figures 2, 3, and 4 illustrate the behavior of optimal equilibrium investment thresholds related to the volatility, risk-free interest rate, and elasticity of the stochastic demand process. The thresholds were recalculated with a fixed $n$ equal to 4 companies, varying the parameters. 


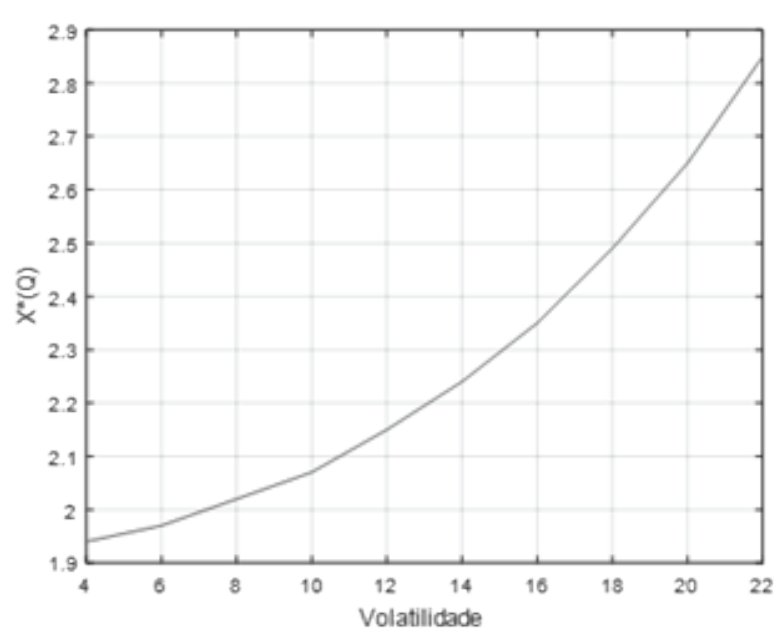

Figure 2: Sensitivity of volatility

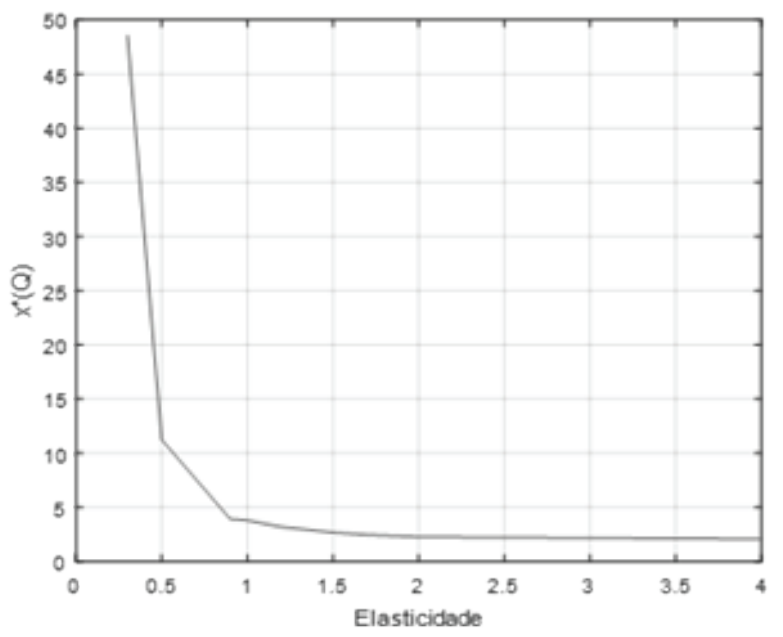

Figure 3: Elasticity of sensitivity

Figure 2 shows that a positive change in the volatility of the GBM positively raises the value of the threshold. This fact is verified in Eq. (23), where the volatility positively affects the last term of the equation as well as the term described by Eq. (19), impacting the threshold in the same direction. Figure 3 illustrates the trend of the threshold from changes in the elasticity of the stochastic demand process, which is a demand function used in the oligopoly model. The elasticity denotes an idea of flexibility of demand with respect to the process $X(t)$.

Thus, the less sensitive real estate buyers are to price changes, the greater the threshold tends to be at equilibrium. The model is less sensitive to variations in elasticity when it is greater than or equal to one. This fact is consistent with the classical concept of elasticity addressed by the microeconomic literature. The model developed from a different specification for stochastic demand produced an optimum threshold in Nash equilibrium from the point of view of economic interpretations, providing more information about the way that thresholds can continue allowing companies to adjust their production.

In addition, the results obtained in this paper can be compared (besides with the Grenadier model) to the result found by Williams (1993), which shares the same general property, demonstrating that there is a decrease in the value of the threshold due to increased competition.

From the sensitivity analyses it was possible to notice that, in the model developed in this article, the optimal threshold is less sensitive to the parameter variations when compared to the threshold found by Grenadier.

\section{Conclusions}

The capital investment decisions of companies are, in most cases, taken within an environment of strategic competition with other companies in the sector, where the actions of one company affect the decisions of the others. In this article, we analyzed how the combination of Game Theory and Real Options can contribute to the economic analysis of investments in new projects in the real estate market, supporting the process of decision making by managers.

This paper makes contributions to the literature by modifying the Grenadier model to a more adequate specification of the uncertainty in demand that allowed more robust economic interpretations regarding the demand for real estate, showing quantitatively how competition can impact strategic decisions.

The results found for properties located in a region of the city of Rio de Janeiro indicated that the optimal strategies for new investments 
in real estate projects is to invest at an optimum threshold in Nash equilibrium in the amount of $\mathrm{R} \$ 4.74$ per unit of investment in the case of a duopoly and at a threshold of $\mathrm{R} \$ 3.77$ for an oligopoly of 5 companies. In the case of an oligopoly with 10 rivals, the optimal strategy is to invest at an optimal threshold equal to $\mathrm{R} \$$ 3.44 per unit of investment. These investment strategies are important to real estate investors as the results indicate that Nash equilibrium thresholds allow for incremental increases in real estate construction whenever a shock to demand reaches the optimal threshold found through the analytical solution provided in this article.

From the results obtained for the option exercising strategies it was possible to compare oligopolies in terms of investment and production levels, showing the evolution of demand for the oligopoly structure, and indicating that the total production was higher in the case of an oligopoly with ten competitors than for duopolies and monopolies.

The results of this study may be useful for the different economic agents involved in real estate in Rio de Janeiro. Public policies that encourage the participation of a larger number of real estate companies would contribute to increased tax collection, since the results suggest that the investment in and production of residential apartments was greater for an oligopoly formed by 10 companies than in the case of monopolies and duopolies. For real estate developers, the results indicate that increased competition reduces the value of the waiting option and the optimal threshold for investment, which leads companies to exercise their options earlier, increasing the number of properties but reducing their price. On the other hand, real estate investment by companies has been very sensitive to variations in the elasticity of demand, which also has impacts on buyers and investors.

The exercise strategies in equilibrium were calculated assuming that the construction of the residential buildings would take place immediately. In order for the model to better represent the practices of the residential real estate market, future research could include the impact of taxes and construction time, as an important feature of real estate investments is the long time to completion.

\section{Acknowledgments}

Marco A.G. Dias thanks Petrobras / Cenpes for its financial support through the FlexWell project. This study was financed in part by the Coordenação de Aperfeiçoamento de Pessoal de Nível Superior - Brasil (CAPES) - Finance Code 001.

\section{References}

Aguerrevere, F. L. (2009). Real options, product market competition, and asset returns. Journal of Finance, 64(2), 957-983. doi:10.1111/j.15406261.2009.01454.x

Baldursson, F. M. (1998). Irreversible investment under uncertainty in oligopoly. Journal of Economic Dynamics \& Control, 22(4), 627-644. doi:10.1016/s0165-1889(97)00070-5

Bloomberg (2017). Bloomberg terminal. Retrieved from https://www.bloomberg.com.br/

Chevalier-Roignant, B., \& Trigeorgis, L. (2011). Competitive strategy: Options and games. Cambrige: Mass: MIT Press.

Costa, F. A., \& Samanez, C. P. (2008). Teoria dos jogos e opçóes reais: Uma aplicação no mercado imobiliário brasileiro. Revista Brasileira de Economia de Empresas, 8(2), 57-62.

Costa, L. D., Azevedo, F. P., \& Samanez, C. P. (2015). Investment strategies in the Brazilian industry of aluminum cans: An analysis in the context of real options games. RBGN-Revista Brasileira de Gestao de Negocios, 17(57), 12461263. doi:10.7819/rbgn.v17i57.2253

Dias, M. A. G. (2015). Análise de Investimentos com opçóes reais: Teoria e prática com aplicaçóes em petróleo e em outros setores (Vol. 2). Rio de Janeiro: Interciência. 
Dixit, A. K., \& Pindyck, R. S. (1994). Investment under uncertainty. New Jersey: Princeton University Press.

Fortunato, G., Brandao, L. E. T., Rozenbaum, S., \& Rebello, A. P. (2008). Valor da opcao de abandono em lancamentos imobiliarios residenciais. RAC-Electronica, 2(3), 531.

Grenadier, S. R. (1996). The strategic exercise of options: Development cascades and overbuilding in real estate markets. Journal of Finance, 51(5), 1653-1679. doi:10.2307/2329533

Grenadier, S.R. (2000). Option Exercise Games: The Intersection of Real Options and Game Theory. Journal of Applied Corporate Finance, 13(2), 99-107.

Grenadier, S. R. (2002). Option exercise games: An application to the equilibrium investment strategies of firms. Review of Financial Studies, 15(3), 691-721. doi:10.1093/rfs/15.3.691

Grenadier, S. R. (2005). An equilibrium analysis of real estate leases. Journal of Business, 78(4), 1173-1213.

Holland, A. S., Ott, S. H., \& Riddiough, T. J. (2000). The Role of uncertainty in investment: An examination of competing investment models using commercial real estate data. Real Estate Economics, 28(1), 33-64. doi:10.1111/15406229.00792

Huisman, K. (2000). Technology investment: A game theoretic real options approach. Netherlands: Tilburg University.

Leahy, J. V. (1993). Investment in competitive equilibrium: The optimality of myopic behavior. Quarterly Journal of Economics, 108(4), 11051133. doi: $10.2307 / 2118461$

Murto, P., Näsäkkälä, E., \& Keppo, J. (2004). Timing of investments in oligopoly under uncertainty: A framework for numerical analysis. European Journal of Operational Research, 157(2), 486-500. doi:10.1016/S0377-2217(03)00234-0
Pindyck, R. S. (1999). The long-run evolution of energy prices. Energy Journal, 20(2), 1-27.

Porter, M. E. (1992). Capital disadvantage: America's falling capital investment system. Harvard Business Review, 70(5), 65-82.

Quigg, L. (1993). Empirical testing of real option pricing models. Journal of Finance, 48(2), 621640. doi:10.1111/j.1540-6261.1993.tb04730.x

Rocha, K., Salles, L., Garcia, F. A. A., Sardinha, J. A., \& Teixeira, J. P. (2007). Real estate and real options: A case study. Emerging Markets Review, 8(1), 67-79. doi:10.1016/j.ememar.2006.09.008

SECOVI-Rio. (2015). Panorama do mercado imobiliário do Rio de Janeiro 2015. Rio de Janeiro: Secovi Rio.

Smit, H. Y. J., \& Ankum, L. A. (1993). A real options and game-theoretic approach to corporate investment strategy under competition. Financial Management, 241-250.

Thijssen, J. J. J., Huisman, K. J. M., \& Kort, P. M. (2012). Symmetric equilibrium strategies in game theoretic real option models. Journal of Mathematical Economics, 48(4), 219-225. doi:10.1016/j.jmateco.2012.05.004

Titman, S. (1985). Urban land prices under uncertainty. The American Economic Review, 75(3), 505-514.

Wang, K., \& Zhou, Y. (2006). Equilibrium real options exercise strategies with multiple players: The case of real estate markets. Real Estate Economics, 34(1), 1-49. doi:10.1111/j.15406229.2006.00158.x

Williams, J. (1991). Real state development as an option. Journal of Real Estate Finance and Economics, 4(2), 191-208.

Williams, J. (1993). Equilibrium and options on real assets. The Review of Financial Studies, 6(4), 825-850. 


\section{Appendix - Steps to obtain equation 3 using the replicating portfolio method}

Let $\mathrm{V}^{\mathrm{i}}\left(\mathrm{X}, q_{i}, Q_{-i}\right)$ be the equilibrium value for each firm with profit flow $\pi\left(X, q_{i}, Q_{-i}\right)$. A replicating portfolio is built for the risk and return of the firm so that it invests $\$ 1$ in assets without risk and buys $n$ units of properties at the price $X(\$ \eta X)$ with a cost of $(1+n X)$, maintaining it for a period of time .

The return of this portfolio will be the value of $\$ 1$ at the risk-free rate $\mathrm{r}$ in $d t=r d t$ e $\$ \eta X$ and invested during $d t$, which yields $\eta X \delta d t$ (dividend) plus a capital gain of $n d x . X(t) . X(t)$ randomly follows a GBM, therefore: $d X=\alpha X d t+\sigma X d z$.

Thus, $n d X=\eta \alpha d t+\eta \sigma X d z$. With this, the total return will be:

$$
r d t+\eta X \delta d t+n d X=(r+\eta(\alpha+\delta) X) d t+\eta \sigma X d z
$$

To obtain the portfolio's return rate, the total return for the initial investment is divided as such: $\frac{\mathrm{r}+\eta \mathrm{X}((\alpha+\delta)}{1+\eta \mathrm{X}} \mathrm{dt}+\frac{\sigma \mathrm{X} \eta}{1+\eta \mathrm{X}} \mathrm{dz}$. The notations $\mathrm{V}^{\mathrm{i}}\left(\mathrm{X}, q_{i}, Q_{-i}\right)$ and $\pi\left(X, q_{i}, Q_{-i}\right)$ will be changed to $\mathrm{V}^{\mathrm{i}}$ and $\pi(X, t)$, respectively.

Comparing to an investment in company $i$, the cost of investment is equal to $\$ \mathrm{~V}^{\mathrm{i}}(X, t)$ and the return is given by:

- Dividend in $d t=\pi(X, t)$, which has no risk (deterministic)

- $\quad$ Capital gain $=d V^{i}(X, t)$, with risk (stochastic)

Using Ito’s Lemma:

$$
d V^{i}=\left[\alpha X \frac{\partial V^{i}}{\partial X}+\frac{1}{2} \sigma^{2} X^{2} \frac{\partial^{2} V^{i}}{\partial X^{2}}+\frac{\partial V^{i}}{\partial t}\right] d t+\sigma X \frac{\partial V^{i}}{\partial X} d z
$$

The total return will be: $\frac{\pi(X, t) d t+d V^{i}}{V^{i}(X, t)}$. Substituting the term, separating the deterministic part from the stochastic part, and changing the notation of the partial derivatives, the expression for the return becomes:

$$
\frac{\pi(X, t)+\alpha X V_{X}^{i}+1 / 2 \sigma^{2} X^{2} V_{X X}^{i}+V_{t}^{i}}{V^{i}(X, t)} d t+\frac{V_{X}^{i} \sigma X}{V^{i}(X, t)} d z
$$

Thus, for both investments to have the same risk, the risky portion must be equal in both cases: $\frac{\sigma \mathrm{X} \eta}{1+\eta \mathrm{X}} \mathrm{dz}=\sigma X \frac{\partial V^{i}}{\partial X} d z$. Therefore: 


$$
\frac{\mathrm{X} \eta}{1+\eta \mathrm{X}}=\frac{\partial \mathrm{V}^{\mathrm{i}}}{\partial \mathrm{X}}
$$

In the market, assets with the same risk should have the same return. Thus, the risk-free returns can be equalized:

$$
\begin{gathered}
\frac{\pi(X, t)+1 / 2 \sigma^{2} X^{2} V_{X X}^{i}+\alpha X V_{X}^{i}+V_{t}^{i}}{V^{i}(X, t)} d t=\frac{r+\eta(\alpha+\delta) X}{1+\eta X} . \\
\frac{r+\eta(\alpha+\delta) X}{1+\eta X}=\frac{r(1+\eta X-\eta X)+\eta X(\alpha+\delta)}{1+\eta X}=\frac{r(1+\eta X)-r \eta X}{1+\eta X}+\frac{\eta X(\alpha+\delta)}{1+\eta X} \\
\frac{r(1+\eta X)}{1+\eta X}-\frac{r \eta X}{1+\eta X}+\frac{\eta X(\alpha+\delta)}{1+\eta X}=r\left(1-\frac{\eta X}{1+\eta X}\right)+\frac{(\alpha+\delta) \eta X}{1+\eta X}
\end{gathered}
$$

Substituting (A-1) into (A-3):

$$
r\left(1-\frac{\eta X}{1+\eta X}\right)+\frac{(\alpha+\delta) \eta X}{1+\eta X}=r\left(1-\frac{\eta X}{1+\eta X}\right)+(\alpha+\delta) \frac{V_{X X}^{i}}{V^{i}(X, t)}
$$

and substituting the result for (A-2), we have:

$$
\frac{r+\eta X(\alpha+\delta)}{1+\eta X}=r\left(1-\frac{V_{X}^{i} X}{V^{i}(X, t)}\right)+(\alpha+\delta) \frac{V_{X}^{i} X}{V^{i}(X, t)}=\frac{\pi(X, t)+1 / 2 \sigma^{2} X^{2} V_{X X}^{i}+\alpha X V_{X}^{i}+V_{t}^{i}}{V^{i}(X, t)}
$$

Rewriting and simplifying, we arrive at the partial differential equation:

$$
\frac{1}{2} \sigma^{2} X^{2} V_{X X}^{i}+(r-\delta) X V_{X}^{i}-r V^{i}+V_{t}^{i}+\pi(X, t)=0
$$

However, for valuation models of real estate projects, we work with perpetual purchase options, with no deadline to exercise the option. Thus, it can be considered that $V_{t}^{i}=0$, since the mere passage of time does not affect the value of $\mathrm{V}$, which would continue with a perpetual horizon to exercise the option. Thus the PDE becomes an ODE, where the term $r-\delta$ f Eq. (A-4) is represented by $\mu$. Returning to the notation $\mathrm{V}^{\mathrm{i}}\left(\mathrm{X}, q_{i}, Q_{-i}\right)$ and $\pi\left(X, q_{i}, Q_{-i}\right)$, we get Eq. (3) from section 3.1 of this article:

$$
\frac{1}{2} \sigma^{2} X^{2} V_{X X}^{i}+\mu X V_{X}^{i}-r V^{i}+\pi_{i}\left(X, q_{i}, Q_{-i}\right)=0
$$


About the Authors:

1. Glaudiane Lilian de Almeida, PhD in Production

Engineering, Pontifical Catholic University of Rio de Janeiro, Rio de Janeiro, Brazil. E-mail:

glaudianealmeida@gmail.com

ORCID

(iD) 0000-0001-5550-8360

2. Marco Antonio Guimaráes Dias, $\mathrm{PhD}$ in Production Engineering, Pontifical Catholic University of Rio de Janeiro, Rio de Janeiro, Brazil. E-mail: marcoagd08@gmail.com

ORCID

(iD)0000-0003-0852-0716

3. Luiz Eduardo T. Brandáo, PhD in Production Engineering, Pontifical Catholic University of Rio de Janeiro, Rio de Janeiro, Brazil. E-mail: brandao@iag.puc-rio.br

ORCIID

(D)0000-0002-5389-0583

4. Carlos Patricio Mercado Samanez (in memoriam), PhD in Finance, Fundação Getúlio Vargas - SP, Administration Department, São Paulo, Brazil. E-mail: cps@puc-rio.br

ORCIID

(iD) 0000-0003-4218-2562

\section{Contribution of each author}

\begin{tabular}{lcccc}
\hline Contribution & $\begin{array}{c}\text { Glaudiane Lilian } \\
\text { de Almeida }\end{array}$ & $\begin{array}{c}\text { Marco Antonio } \\
\text { Guimaráes Dias }\end{array}$ & $\begin{array}{c}\text { Luiz Eduardo T. } \\
\text { Brandáo }\end{array}$ & $\begin{array}{c}\text { Carlos Patricio } \\
\text { Mercado } \\
\text { Samanez }\end{array}$ \\
\hline $\begin{array}{l}\text { 1. Definition of research problem } \\
\text { 2. Development of hypotheses or research questions }\end{array}$ & $\sqrt{ }$ & & & $\sqrt{ }$ \\
(empirical studies) & & $\sqrt{ }$ & & \\
$\begin{array}{l}\text { 3. Development of theoretical propositions } \\
\text { (theoretical work) }\end{array}$ & $\sqrt{ }$ & $\sqrt{ }$ & $\sqrt{ }$ \\
4. Theoretical foundation/ Literature review & $\sqrt{ }$ & $\sqrt{ }$ & $\sqrt{ }$ \\
5. Definition of methodological procedures & $\sqrt{ }$ & $\sqrt{ }$ & \\
6. Data collection & $\sqrt{ }$ & $\sqrt{ }$ & & \\
7. Statistical analysis & $\sqrt{ }$ & $\sqrt{ }$ & $\sqrt{ }$ \\
8. Analysis and interpretation of data & & $\sqrt{ }$ & \\
9. Critical revision of the manuscript & $\sqrt{10}$ Manuscript writing & & & \\
10.
\end{tabular}

